coloproctology 2014 · 36:249

DOI 10.1007/s00053-014-0476-3

Online publiziert: 16. Juli 2014

(c) Springer-Verlag Berlin Heidelberg 2014

\title{
M. Fried
}

Klinik für Gastroenterologie und Hepatologie, UniversitätsSpital Zürich

\section{In memoriam Prof. Dr. Martin Zeitz}

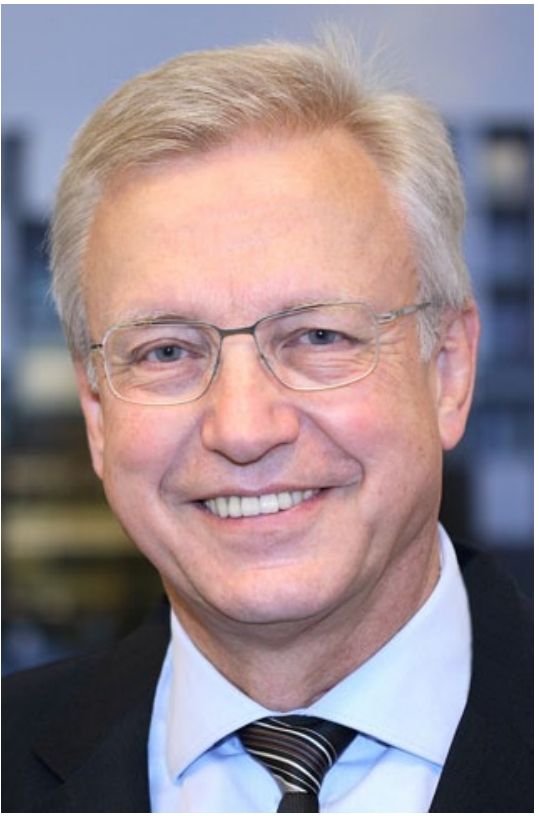

Prof. Dr. Martin Zeitz

Martin Zeitz zählte zu den ganz großen Gastroenterologen unserer Zeit. Er war ein überragender Wissenschaftler, ein großartiger Lehrer, eine integrierende Persönlichkeit und dabei ein Mensch, der sich nie selber in den Vordergrund stellte, sondern aus dem Hintergrund lenkte und Schwerpunkte setzte. Bescheidenheit gehörte zu seinen wichtigen Charaktereigenschaften, gepaart mit Empathie und großem Engagement für seine Patienten und Mitarbeiter.

Martin Zeitz hat in der immunologischen Forschung, im Bereich der chronisch-entzündlichen Darmerkrankungen wichtige Akzente gesetzt und neue Richtungen aufgezeigt, die für Generationen von Klinikern und Forschern richtungsweisend sind. Er verkörperte die ideale
Kombination eines Klinikers und grundlagenorientierten Forschers und war damit einer der Pioniere eines translationalen Forschungsansatzes. Martin Zeitz war auch ein fähiger Manager: Als Ärztlicher Leiter des Charité Zentrums für Magen-, Darm-, Nieren- und Stoffwechselmedizin und zuletzt als Ärztlicher Direktor des Universitätsklinikums Eppendorf verstand er sich als Diener seiner Institution, seiner Mitarbeiter und nicht zuletzt der Patienten, die für ihn immer im Vordergrund seiner Arbeit standen. Die Förderung des Nachwuchses war ihm immer eine Herzensangelegenheit.

Mit Martin Zeitz verlieren wir einen großartigen Menschen, einen außergewöhnlichen Arzt, Wissenschaftler und Lehrer. Martin Zeitz ist viel zu früh von uns gegangen, er fehlt uns, seinen Schülern, seinen Mitarbeitern, seinen Freunden und vor allem seiner Familie. Wir werden ihm ein ehrendes Angedenken bewahren.

\section{Korrespondenzadresse}

Prof. Dr. M. Fried

Klinik für Gastroenterologie und Hepatologie,

UniversitätsSpital Zürich

Rämistr. 100, 8091 Zürich

Schweiz

michael.fried@usz.ch 